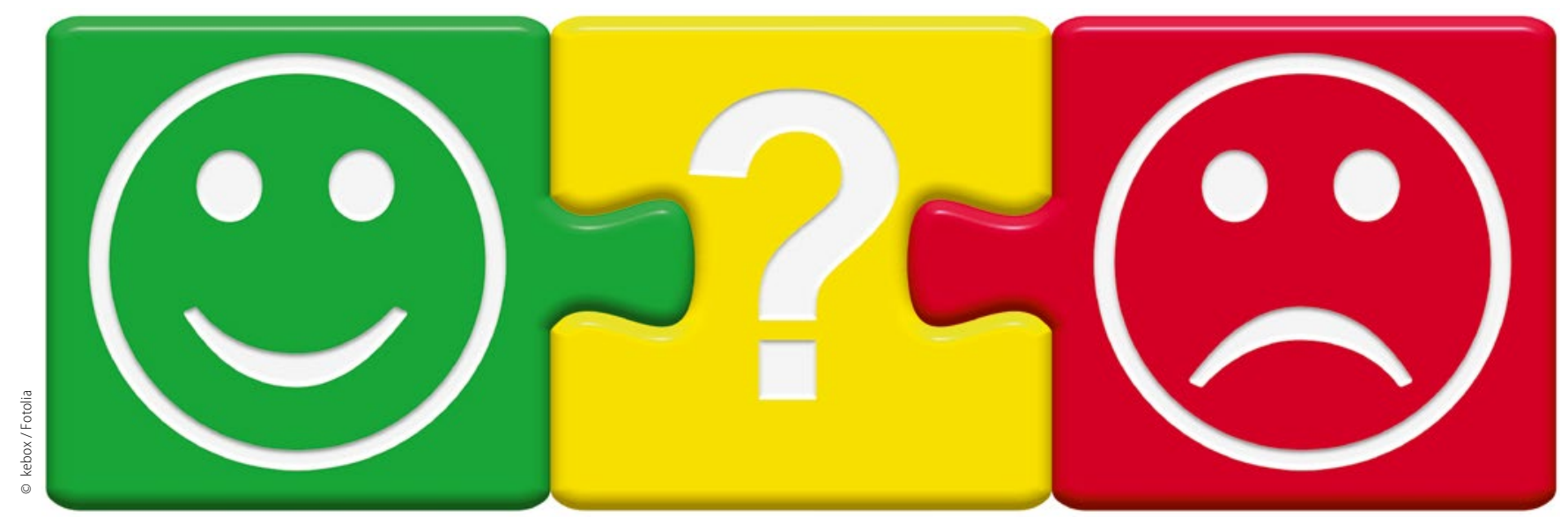

\title{
Bundesgerichtshof stärkt mit Urteil die zahnärztliche Position
}

\author{
Der Bundesgerichtshof (BGH) hatte in einem aktuellen Fall erneut zum Thema \\ (Zahnärzte-)Bewertungsportale zu entscheiden. Erstmals hat das höchste deutsche \\ Zivilgericht dabei eine zahnarztfreundlichere Linie gewählt.
}

\section{Der Fall}

Der Kläger ist als Zahnarzt niedergelassen. Er hatte auf dem Portal Jameda von einem anonymen Patienten eine negative Bewertung mit der Gesamtnote 4,8 erhalten. Als Teilnote war für die Bereiche „Behandlung“, „Aufklärung“ und „Vertrauensverhältnis“ jeweils die Note 6,0 (also ungenügend) vergeben worden. Der Zahnarzt verlangte von Jameda die Löschung, die Jameda verweigerte. In erster Instanz obsiegte der Zahnarzt, das Berufungsgericht entschied zugunsten von Jameda.

\section{Die Entscheidung}

$\mathrm{Zu}$ Unrecht, wie der BGH unter Aufhebung des zweitinstanzlichen Urteils ausweislich seiner Pressemitteilung jetzt entschied (Urteil vom 01.03.2016, Az.: 34/15) und die Sache zur weiteren Verhandlung zurückverwies. Einleitend stellt der BGH entsprechend seiner bisherigen Linie fest, dass sich Jameda die auf seinem Portal abgegebenen Bewertungen nicht zu eigen mache. Eine Haftung der Plattform komme deshalb nur in Betracht, wenn Jameda zumutbare Prüfpflichten verletze. Was zumutbar sei, hänge von den Umständen des Einzelfalls ab. In jedem Fall dürften die Prüfungspflichten nicht so weit gehen, dass das Geschäftsmodell von Jameda per se gefährdet werde.

Nach diesen Maßstäben hätte Jameda im zu entscheidenden Fall aber jedenfalls überprüfen müssen, ob der User überhaupt bei dem bewerteten Zahnarzt in Behandlung gewesen ist. Hierzu hätte Jameda bei seinem User Behandlungsunterlagen anfordern und diese jedenfalls insoweit dem Kläger anonymisiert zugänglich machen müssen, als diese Weiterleitung nicht gegen sonstige Gesetze, insbesondere das Telemediengesetz, verstoßen würde. Der BGH verwies den Fall an das Oberlandesgericht Köln zurück, um die ergriffenen Prüfungsmaßnahmen zu überprüfen.

Die vollständigen Gründe des Urteils liegen bisher nicht vor. Insofern ist auch nicht eindeutig, ob die Prüfpflichten des Portals hier deshalb ausgedehnt wurden, weil es aufgrund der Umstände des Einzelfalls besonders nahelag, dass der User von dem Kläger gar nicht behandelt wurde. Die allgemeine Begründung des BGH für die Prüfpflicht, Bewertungsportale trügen ein hohes, durch die Anonymität gesteigertes Risiko von Persönlichkeitsrechtsverletzungen in sich, lässt allerdings eher darauf schließen, dass das Urteil grundlegende Bedeutung hat. Näheres wird sich nach Vorlage der Urteilsbegründung sagen lassen.

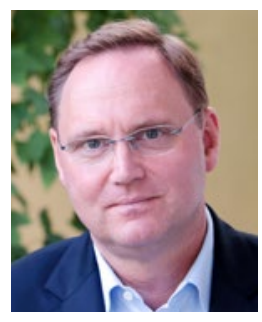

RA Michael Lennartz

www.lennmed.de 